\begin{tabular}{cc}
\hline International Journal of Engineering \& Technology, $7(2.15)(2018) 1-7$ \\
SPC \\
Website: www.sciencepubco.com/index.php/IJET \\
Research Paper \\
\hline
\end{tabular}

\title{
Development of Spatial Distribution Model using GIS to Identify Social Support Index Among Drug-Abuse Inmates
}

\author{
Mahadzirah Mohamad ${ }^{1}$, Mohd Khairul Amri Kamarudin ${ }^{2 *}$, Hafizan Juahir ${ }^{2}$, Nor Azman Mat Ali' ${ }^{1}$, Fazida Ka- \\ rim¹, Nurhikmah Badarilah', Norhilmi Muhammad', Muhammad Syaakir Mohd Ridzuan' \\ ${ }^{1}$ Faculty of Economics and Management Science, Universiti Sultan Zainal Abidin, Kuala Gong Badak Campus, \\ 21300 Kuala Nerus, Malaysia \\ ${ }^{2}$ East Coast Environmental Research Institute (ESERI), Universiti Sultan Zainal Abidin, Gong Badak Campus, \\ 21300 Kuala Nerus, Malaysia \\ *Corresponding author E-mail: mkhairulamri@unisza.edu.my
}

\begin{abstract}
This study was to identify the spatial distribution of Social Support Index (SSI) among drug-abuse inmates throughout Peninsular Malaysia. Factor Analysis (FA) and Discriminant Analysis (DA) were applied to analyses the level of social support (SS) among drug-abuse inmates and develop the spatial model using Geographic Information System (GIS). Five significant index categories were generated from FA: excellent, good, moderate, low and poor Quality of Life Index (QoLi) and the nine of SS variables are expected to be derived from family, friends and other social factor. DA showed each category differed from others in terms of different compositions, stepwise backward and forward modes gave $99.75 \%$ correct classification. GIS analysis show the distribution of SSI categorized on family and friends factor were moderately for where the prisoners came. Besides that, Perlis classified as low-level index and Melaka as high-level index of other social factor. The distribution model of SSI in moderately-level showed Jelebu, Sungai Petani, Pengkalan Chepa and Simpang Renggang as the better SS factor to quality of life compared to the Penor, Pahang. The procedures of FA, DA and GIS were used in this study proved the source apportionment of SS and QoLi among drug-abuse inmates in Peninsular Malaysian prisons.
\end{abstract}

Keywords: Social support; Quality of life; Factor Analysis; Discriminant Analysis; Spatial Distribution Model; GIS.

\section{Introduction}

For the last 15 years, the world prison population rate has risen by about $6 \%$ from 136 per 100,000 of the world population to the current rate of 144. Globally, more than 10.2 million inmates are held in prison throughout the world. Besides, there are approximately 43,388 inmates in Malaysia prison Institution [1]. Notably, drugabuse inmates frequently represent a large part of the prison population [2]. Equally, drug-abuse inmates is one of the primary problems in the world [3], and remain to be a prominent delinquent in Malaysia with $59.9 \%$ inmates in Malaysian prison population charged for various drug-abuse offenses [4]. Most of inmates connected with various health risks, higher depression and death [5-7]. Most of inmates are from poor communities and vulnerable social groups [8]. Inmates experienced a lot of difficulties in their lives such as violent relationships, addiction, and mental health problems like depression and burnout [9]. Furthermore, while incarcerated, many inmates lose their home and employment placements, financial problems, and lose contact with their family [10]. Thus, Inmates in prison experienced the lowest life satisfaction and the highest sense of defeat [11]. There are substantial research states that support, rehabilitation, and supervision programs can be effective in reducing recidivism rates. For examples, a social support structure is considered fundamental to inmate's adjustment and ability to cope with life during incarceration [12]. The idea that social interaction and engagement with institutions and social networks in terms of formal and informals, giving a lot of benefits [13]. Hence, a study by Harp et al. (2012) [14] found that inmates who perceived as having social support during and after imprisonment were more likely to have a source of income, had fewer daily problems and were more satisfied with life. Social support may be described as having a family and a network of close friends who provide social and emotional attachment, and the feeling of being able to depend on them for all physical and emotional needs.

Family permanency and emotional support from home can effect an inmate's chance of success in a number of ways. Families provide not only emotional support to boost the inmate to maintain a upstanding life but in terms of housing and financial support as well [15]. Offenders who have higher levels of social support throughout their prison sentence have decreased chances of recidivating in comparison to offenders who do not sustain these relationships while incarcerated [16]. Some prisons stressed the importance of visitation for inmates, because of the benefits for both offender and community, where community will see upon the offender release when they stops from commit crime.

According to Drago et al. (2011) [17], only a small proportion of inmates receive visits during imprisonment. For those who are come from disadvantaged neighborhoods, distance may constitute an especially significant barrier to maintaining social ties. Families, for example, may have difficulty to enable travel because of certain limitations of resources from their behalf. Many studies have found that visitation is associated with inmate behaviour and enhanced quality of life upon release [18-19]. Visitation may reduce strain and increase social bonds, and in turn reduce misconduct and recidivism, and improve other reentry outcomes [20]. Hence, social support has to be addressed in order to increase the inmates' quality of life and help them to reintegrate into community after being 
released from prison. Therefore, in order to reach the targeted objective and aim, research had been done among drug-abuse inmates all over Peninsular Malaysia prisons to collect data on social support among drug-abuse inmates. The data collected were analysed using several tools to get the accurate analysis pertaining to the partial distribution of social support index among drug-abuse inmates Geographic Information System (GIS) and Multivaried Data Analysis tools will be used to help and analyse the data in this study. GIS is a comprehensive collection of tools for capturing, storing, retrieval, transformation and visualization of spatial data of the real world for special applications [21]. GIS can be synthesized and presented in form of three distinct but overlapping views which ArcMap, data-based and spatial analysis view [22]. Over the years, the availability and sophistication of GIS were growing and thus give a huge influence on the approaches available in the study of health geographically. These improvements really help researchers in monitoring and responding to health challenges.

Nowadays, GIS tools for performing spatial analysis has become more available to social science studies. The research by Mustafa et al. (2015) [23] shows that GIS can be used to map where a person with certain characteristics or diseases live, and thus help health researchers and practitioners detect and identify hot spots for certain diseases and take precaution against them. Brownstein et al. (2010) [24] is another example of research that are using this method to identify hot spots of potential opioid medication abuse. Statistical technique used to analyse data that arises from more than one variable or known as multivariate data analysis, where this essentially models' reality to where each situation, product, or decision involves more than a single variable. D'Ovidio (2014) [25], used multivariate analysis to explore customer characteristics and their quality perception in his study. Thus, for a reliable classification of drug-abused inmates based on their state and spatial model, this research will underline on multivariate analysis method. This is important as disorganised social and spatial arrangement create a problem with social exclusion [26] especially when reintegrating to community.

\section{Materials and Method}

\subsection{Study Area and Population}

The data were collected through interviews during the period April and June 2015 by using a structured questionnaire where twelve (12) prisons were selected in Peninsular Malaysia. The response was measured using a ten point Likert scale that ranged from one for strongly disagree to ten for strongly agree. Since these prisons are widely scattered in term of geographical location, the study applied area sampling method whereby Peninsular Malaysia is divided into four areas; Eastern Region, Northern Region, Southern Region and Central Region. The Eastern Region consists of Kelantan (Pengkalan Chepa), Terengganu (Marang) and Pahang (Bentong and Penor) prisons. The Northern Region consists of Kedah (Pokok Sena and Sunga Petani) and Pulau Pinang (Seberang Perai) prisons. The Southern Region consists of Johor Bharu (Kluang and Simpang Renggam).

Last, prisons in Central Region consists of Selangor (Kajang), Negeri Sembilan (Seremban and Jelebu) and Perak (Tapah) prisons. The exact location for every prisons selected is shown in fig. 1. Generated through SPSS, the respondents were selected from sampling frame using the random numbers once the prison is selected.

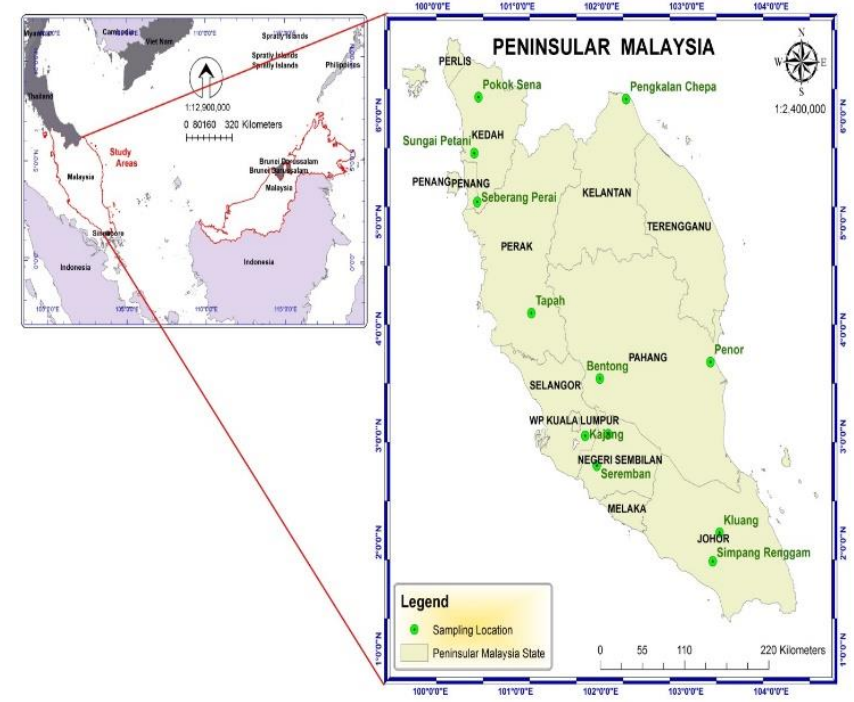

Fig. 1: Study areas and exact location for every prisons selected in Peninsular Malaysia, Malaysia.

\subsection{Database Design}

\section{A) Geographic Information System (GIS)}

GIS is a system organized as a combination of software and hardware that is capable of capturing and recording information (data), storing and checking, manipulating and analysing that information retrieved and displaying it in accordance with spatial reference to the Earth [27-28]. For this study, the developed GIS database design consists of two different types of information involving the identification of information required for the GIS analysis viz, spatial database design and attribute database design.

The spatial database includes vector type where the spatial data is directorial district boundary of Malaysia, stored as polygon, while, attribute database includes index of social support among drug-addicted person by state in Malaysia. The attribute dataset is stored in the unified data format (.dbf). Both of the databases are intercorrelated. The special characteristics and the corresponding attribute data are usually connected by user identity code. The keyword used for connecting the attribute database and the spatial database is the field name of administrative district. The topographic map of Malaysia was georeferenced and the root mean square error (RMSE) was found. The measure of precision (RMSE) is used to determine transformation accuracy from one system to another system of coordinates [29]. The formula of RMSE is shown in equation 1:

$R M S E=\sqrt{\frac{1}{2} \sum_{j}^{n}=1\left(y_{j}-\hat{y}_{j}\right)^{2}}$

Where,

Summation is represents by the large sigma character current predictor is represents by $j$ and the number of predictors is represents by $n$.

Spatial and temporal distributions of physical and socioeconomic occurrences can be proximate by functions according to location in a multi-dimensional space, as multivariate scalar, vector, or tensor fields. In order to predict values of spatial phenomena in unsampled locations, many interpolation and estimation methods were established [30]. Interpolation is the phenomena that can be done using various methods and in different ways but depends on the types of data the research is dealing with. Interpolation methods are used to estimate the values obtained from unsampled locations. The field measurements required conversion into continuous space before the mapping and spatial analysis could take place. This can be done using an interpolation method. The most common techniques for interpolation in GIS are: Kriging, Inverse Distance Weighting 
(IDW), Point TIN, and Spline [31-32]. In this study, The IDW interpolation method in GIS will be used to model the spatial distribution of social support among drug-abuse inmates. IDW is among the simplest methods of interpolation. It is based on approximation and assumption of a given value at the unsampled points within several distances or from a given set of numbers. Weights usually decline with the influence of distance (inversely proportional to the weight and distance) [33-35] and are correlated with the equation 2, where $\mathrm{r}$, act as an unsampled location that leads to an estimator as:

$f(r)=\sum_{i=1}^{m} w_{i} z\left(r_{i}\right)=\frac{\sum_{i=1}^{m} w_{i} z\left(r_{i}\right) /|r-r|^{p}}{\sum_{j=1}^{m} 1 /|r-r|^{p}}$

Where, as in many literature, $\mathrm{p}$ is a parameter, where normally, $\mathrm{p}=2$ [36]. However, this basic method is common and easy to implement and is available in almost any GIS. Hence, among the shortcomings of this method are limiting its practical applications and it does not create the local shape implied by data and produces local extreme at the data points.

\section{B) Data Analysis}

In this study, the Multivariate analysis will be analysed using XLSTAT by using the data of social support among drug abuse inmates in Peninsular Malaysia prison. Three types of multivariate analysis applied in this study were factor analysis, discriminant analysis and boxplot analysis. Boxplot analysis was required in this study to determine the range area and the level of social support index receive by drug-abuse inmates by spatial analysis. The observation upon the differences among the groups was achievable.

\section{i) Factor Analysis (FA)}

FA is applied to infer relationships between variables [37]. Varimax method is used in the FA techniques. The varimax rotation ensures that every variable associated with only one principal component as encompassing a near-zero relationship with the other components. Eigenvalues obtained from varimax rotation are the precursor of the FA. Eigenvalues over 1 were considered as significant and subsequently varimax factors (VFs), which are the new groups of variables are produced [38].

The VFs values which are greater than $0.75(>0.75)$ are considered as "strong", the values ranging from $0.50-0.75(0.50 \geq$ factor loadings $\geq 0.75$ ) are considered as "moderate", and the values ranging from $0.30-0.49(0.30 \geq$ factor loadings $\geq 0.49)$ are considered as "weak" factor loadings [39]. Based on different activities in the three significant clustered districts, the emission source recognition of different air pollutants was accomplished. The fundamental model of FA is stated as equation 3:

$Z_{i j=} a_{f 1} f_{1 i}+a_{f 2} f_{2 i}+\cdots+a_{f m} f_{m i}+e_{f i}$

where, $z$ is the measured value of a variable, $a$ is the factor loading, $f$ is the factor score, $e$ is the residual term accounting for errors or other sources of variation, $i$ is the sample number, $j$ is the variable number, and $m$ is the total number of factors.

In order to certify that the attributes are maximally correlated with only one factor and for ease of reading the factors, orthogonal varimax rotation method is applied in this study. To ensure that the factor scores are uncorrelated and to avoid the influence of different measurement scales on the resulting score, the Anderson-Rubine method is employed in identifying the factor score coefficients.

\section{ii) Discriminant Analysis (DA)}

The fundamental point of DA is to classify an object of unknown origin to one of several naturally-occurring groups [40]. For every cluster, it creates a discriminant function (DF) [41]. Then, the DFs can be determined by:

$f\left(G_{i}\right)=k_{i}+\sum_{j-1}^{n} W_{i j} P_{i j}$

where,

$i$ is the number of groups $(\mathrm{G}), k i$ is the constant inherent to each group, $n$ is the number of parameters used to classify a set of data into a given group, and $w j$ is the weight coefficient assigned by DF analysis (DFA) to a given parameter (Pj). In this study, DA was applied on three modes, which are standard mode, forward stepwise mode and backward stepwise mode. A standard mode was done to create DFs for assessing spatial variations in the social support items. In the forward stepwise mode, variables were gradually disregarded from the most significant variable until no significant changes were found. Conversely, in the backward stepwise mode, variables were eliminated gradually, starting with the least significant variable until no significant changes were found.

\section{Results and Discussion}

\subsection{Factor Analysis}

Based on responses from 1,696 drug-abuse inmates completing all nine items, factor analysis was performed. The factors that are shown in Table 1 can be considered as the underlying dimensions of social support among drug-abuse inmates. There were 2 factors with eigenvalues greater than one (Table 2) and they explained approximately $45.79 \%$ (first factor) and $12.85 \%$ (second factor) of the variance respectively. Factor loadings for an analysis forced 2 factors, with rotation are shown in Table 1 . In order to be identified as dimensions, attributes with factor loadings greater than 0.5 are needed. This implies that the data is suitable for factor analysis.

Table 1: Factor loadings from analysis forcing 2 factors

\begin{tabular}{lcc}
\hline \multicolumn{1}{c}{ Item } & \multicolumn{2}{c}{ Varimax Rotation } \\
\cline { 2 - 3 } & Factor 1 & Factor 2 \\
\hline (SS1) There is a special person with whom I & 0.667 & \\
can share my joys & & \\
(SS2) There is a special person with whom I & 0.684 & \\
can share my sorrows. & 0.690 \\
(SS3) My family really tries to help me. & 0.796 & \\
(SS8) I get the emotional help and support I & & 0.730 \\
need from my family. & & 0.851 \\
(SS9) I have a special person who is a real & & 0.524 \\
source of comfort to me. & & \\
(SS4) My friends really try to help me. \\
(SS5) I can count on my friends when things \\
go wrong \\
(SS6) I can talk about my problems with my \\
family \\
(SS7) I have friends with whom I can share my & & \\
joys and sorrows. & & \\
\hline *The varimax rotation strongly suggest a 2-factor solution, with items SS1, SS2, SS3, \\
SS8 and SS9 forming the first factor and items SS4, SS5, SS6 and SS7 forming the \\
second.
\end{tabular}

Table 2: Factor Analysis of drug-abuse inmates

\begin{tabular}{lcc}
\hline & $\mathrm{F} 1$ & $\mathrm{~F} 2$ \\
\hline Eigenvalue & 4.121 & 1.157 \\
Variability $(\%)$ & 45.787 & 12.850 \\
Cumulative \% & 45.787 & 58.638 \\
\hline
\end{tabular}

A) First factor 
This factor can be interpreted as family since it shows high-loading family matters. Family involvement in supporting drug-abuse inmates is increasing along with the score.

\section{B) Second factor}

This factor can be interpreted as friends dimension of social support since it shows high loadings on the "I can count on my friends when things go wrong" and "My friends really try to help me".

\section{C) Social Support Index}

Index of social support is developed in order to reveal the group of social supports (high, good, moderate, poor and low) should be given more attention while designing data-collection schemes. Two selected factors that relate to the dimensions of social support is combined together and the scores is called as social support index. The overall score of each respondent is obtained by weighting each factor score by the respective variance as follows (Eq. 5):

$$
\left(S S_{i}\right)=\left(45.79 \times F_{1}+12.85 \times F_{2}\right) / 100
$$

Where,

$\llbracket S S \rrbracket_{\mathrm{i}}$ is social support score of respondent $\mathrm{i}, \llbracket F \rrbracket_{1}$ is family score and $\mathrm{F}_{2}$ is friends score of respondent $i$.

This implies that the higher the score in the family and friends dimension, the better the social support received by drug-abuse inmates

\subsection{Discriminant analysis (DA)}

Spatial distribution in social support was assessed with the help of DA to examine level of social support index among drug abuse inmates (i.e., Excellent, Good, Low. Moderate and Poor). The five levels of index obtained from FA were considered as dependent variables (index category) to DA. DA showed that each category differed from the others in terms of different compositions as the no confusion matrix occurs on the data set. The results from standard, stepwise backward and stepwise forward modes gave $99.75 \%$ correct classification based on the confusion matrix of the estimation sample (Fig. 2).

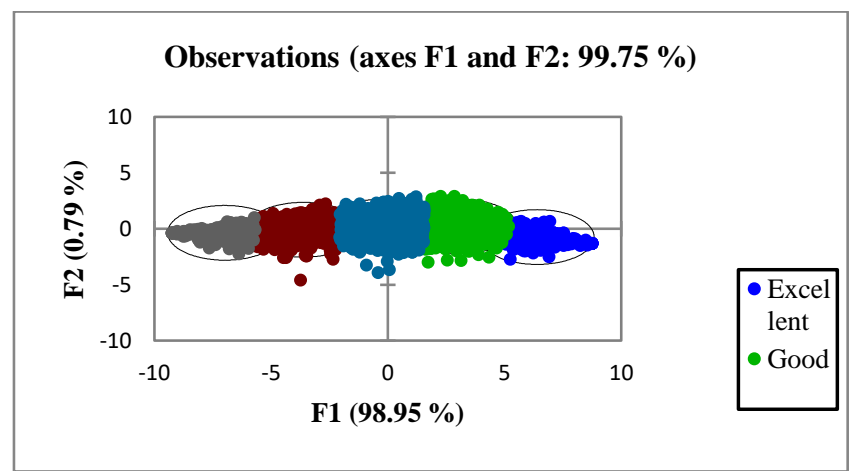

Fig. 2: Confusion matrix for Discriminant analysis (DA) of drug-abuse inmates

Stepwise discriminant analysis was performed as an explanatory analysis to determine the most significant variables among the parameters. In stepwise forward mode, variables were included one by one, beginning with the most significant until no significant changes were obtained, while in stepwise backward mode, variables were removed one by one beginning with the least significant until no significant changes were obtained.
Stepwise backward mode generated $99.35 \%$ correctly with nine discriminant items while stepwise forward mode rendered $99.35 \%$ with also nine discriminant items. However, there is no difference in matching for each group compared with the stepwise backward mode. Therefore, DA results recommended all nine discriminant items as significant in discriminating the level of social support index (Table 3).

Table 3: Confusion matrix for the estimation sample drug-abuse inmates.

\begin{tabular}{lccccccc}
\hline $\begin{array}{l}\text { from } \\
\text { to }\end{array}$ & $\begin{array}{c}\text { Ex- } \\
\text { cel- } \\
\text { lent }\end{array}$ & Good & Low & $\begin{array}{c}\text { Mod } \\
\text { er- }\end{array}$ & Poor & $\begin{array}{c}\text { To } \\
\text { tal }\end{array}$ & $\begin{array}{c}\% \text { cor- } \\
\text { rect }\end{array}$ \\
\hline Excel- & 164 & 0 & 0 & 0 & 0 & 164 & $100.00 \%$ \\
lent & & & & & & & \\
Good & 1 & 462 & 0 & 0 & 0 & 463 & $99.78 \%$ \\
Low & 0 & 0 & 342 & 3 & 1 & 346 & $98.84 \%$ \\
Moderate & 0 & 4 & 0 & 559 & 0 & 563 & $99.29 \%$ \\
Poor & 0 & 0 & 2 & 0 & 156 & 158 & $98.73 \%$ \\
Total & 165 & 466 & 344 & 562 & 157 & 1694 & $99.35 \%$ \\
\hline
\end{tabular}

Table 4 and Fig. 3shows the descriptive statistics of quantitative data of this study. The median, quartile and extreme values have shown the median, quartile and extreme values. The data shown that there are no data which can be considered as an outlier (Fig. 3).

Table 4: Descriptive statistics (Quantitative data) for drug-abuse inmates.

\begin{tabular}{lccccc}
\hline \multicolumn{1}{c}{ Statistic } & Excellent & Good & Low & Moderate & Poor \\
\hline $\begin{array}{l}\text { No. of observa- } \\
\text { tions }\end{array}$ & 164 & 463 & 346 & 563 & 158 \\
Minimum & 8.111 & 6.111 & 2.444 & 4.333 & 1.000 \\
Maximum & 10.000 & 8.556 & 5.000 & 6.667 & 3.000 \\
1st Quartile & 8.556 & 6.778 & 3.444 & 5.111 & 1.889 \\
Median & 8.889 & 7.111 & 3.889 & 5.556 & 2.222 \\
3rd Quartile & 9.333 & 7.556 & 4.222 & 5.889 & 2.528 \\
Mean & 8.959 & 7.191 & 3.854 & 5.541 & 2.120 \\
Variance (n-1) & 0.282 & 0.267 & 0.274 & 0.269 & 0.261 \\
Standard devia- & 0.531 & 0.517 & 0.524 & 0.519 & 0.511 \\
tion (n-1) & & & & & \\
\hline
\end{tabular}

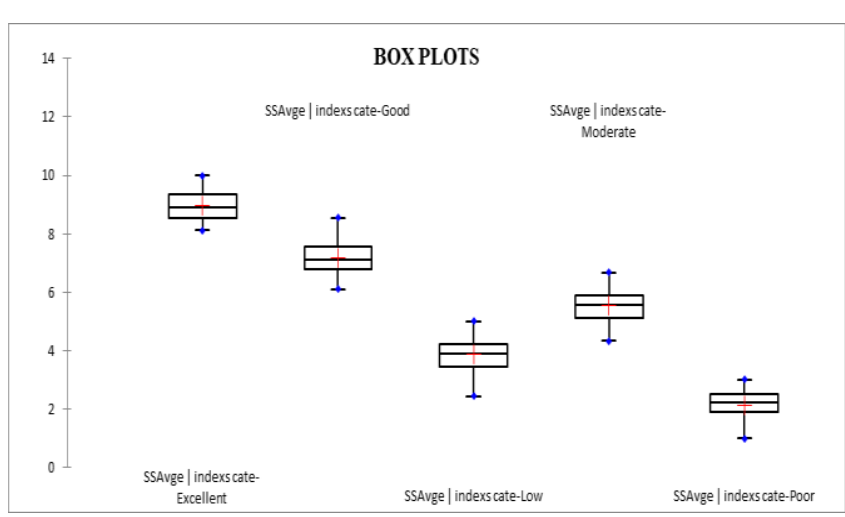

Fig. 3: Boxplots of descriptive statistics for drug-abuse inmates in this study

\subsection{The Spatial Distribution Model of Social Support among Drug-abuse Inmates}

Mapping tools can help with prison management in numerous ways, including quality of life, tracking disciplinary incidents, visitation patterns and medical information, managing gangs and escape threats, and identifying personal information about inmates [14]. GIS helps correctional officials to determine possible sites for building prisons by examining complex, seemingly unrelated 
measures such as demographic physiognomies and displaying them all in a graphical, layered, spatial interface or map. It also helps them map inmate populations, fixtures, and equipment to provide for the safety of inmates by separating gang members, identifying high-risk or potentially violent inmates, and identifying hazardous locations in a prison. Generally, GIS data are thought of as addresses and locations in a community, but they also can be positions of a building or an institution. For GIS to be useful in an institutional setting, a map of the facility must be formed. Once a layout is established, data such as inmate demographics, gang affiliations, locations of assaults and attempted escapes can be incorporated and analysed. Displaying these data spatially can lead to a much better understanding of the events and incidents within certain facility. For example, if there has been a recent series of inmate-on-inmate assaults, GIS can be used to spatially and temporarily analyze the incidents in an attempt to predict or prevent future assaults [42]. In this study, GIS was used to analyse the SSI among drug-abuse inmates at all states in Peninsular Malaysia.

The DA result classified all the nine discriminant items into discriminating levels of social support index at twelve states in Peninsular Malaysia (Table 5). Fig. 4 shows the distribution of SSI for drug-abuse inmates on family factor, friends factor and other social factor of quality of life where the prisoners came from. This study proved all states in Peninsular Malaysia have moderately level on family factors and friends factors of drug-abuse inmates's quality of life. The index of other social factors classified Perlis as low level of SSI and Melaka as good level of SSI. The other social factors such as offender's environment, geographic location, the placement of new facilities within a community and so on. The prisoners who came from Malacca known as having good level of SSI on other social factors of quality of life because may be subjects were more satisfied with emotional support were having someone help them with the encouragement. The geographic and distance factor such as the prisoners from Malacca are located in Seremban and Kajang prison might also contribute to the result.

Table 5: Social Support Index (SSI) in Peninsular Malaysia.

\begin{tabular}{cc}
\hline Level & Social Support Index (SSI) \\
\hline Poor & $-0.911 \geq x<-0.556$ \\
Low & $-0.556 \geq x<-0.201$ \\
Moderate & $-0.201 \geq x<0.154$ \\
Good & $0.154 \geq x<0.509$ \\
Excellent & $\mathrm{x} \geq 0.509$ \\
\hline
\end{tabular}

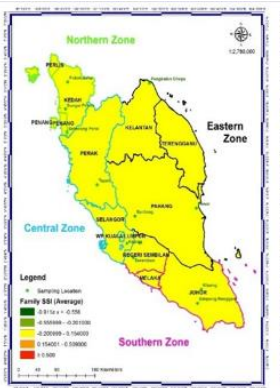

a) Family factor

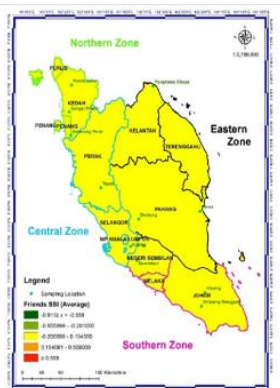

b) Friends Factor

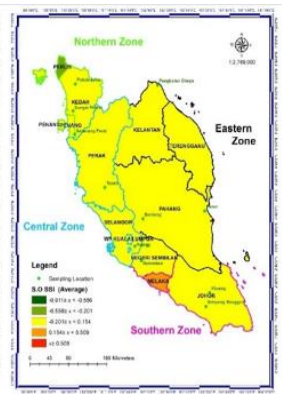

c) Other Social factor
Fig. 4: Distribution model of SSI for drug abuse inmates on family factor, friends factor and other social factor of quality of life where the prisoners came from; a) Family factor, Friends Factor and c) Other Social factor.

Over time, satisfaction with emotional support and tangible support also remained stable. Although not significantly different across time, recipients reported more satisfied with tangible support than emotional support. Compared with other prisoners in Peninsular Malaysia, prisoners from Perlis had a low level of SSI on other social factors of quality of life. Malacca was classified as good level of SSI on other social factors of quality of life in Peninsular Malaysia and other states categorized as moderate level of SSI on other social factors of inmates's quality of life. Melaka is classified as an area with high levels of satisfaction with the quality of life, better than the other states in Peninsular Malaysia, especially Perlis, mainly due to geographical factors. Malacca is located in the west part of Peninsular Malaysia where communities are more openminded.

Fig. 5 shows the detail distribution model of SSI for drug-abuse at prisons in moderate category in Peninsular Malaysia. This study proved the SSI at Jelebu and Seremban (near Malacca) had the better quality of life for drug-abuse inmates The growth and environment at Jelebu prison maybe more comfortable and have better facilities. Because of that, the level of satisfaction and emotional support for drug-abuse inmates in Melaka prison was higher than other states in Peninsular Malaysia. In general, the Sungai Petani (Kedah) Pengkalan Chepa (Kelantan) and Simpang Renggam (Johor) also had the better social support factor to quality of life for drug-abuse inmates compared to Penor (Pahang). The level of quality of life for drug-abuse inmates in Penor prison is poor compared of other prison's moderate category in Peninsular Malaysia.

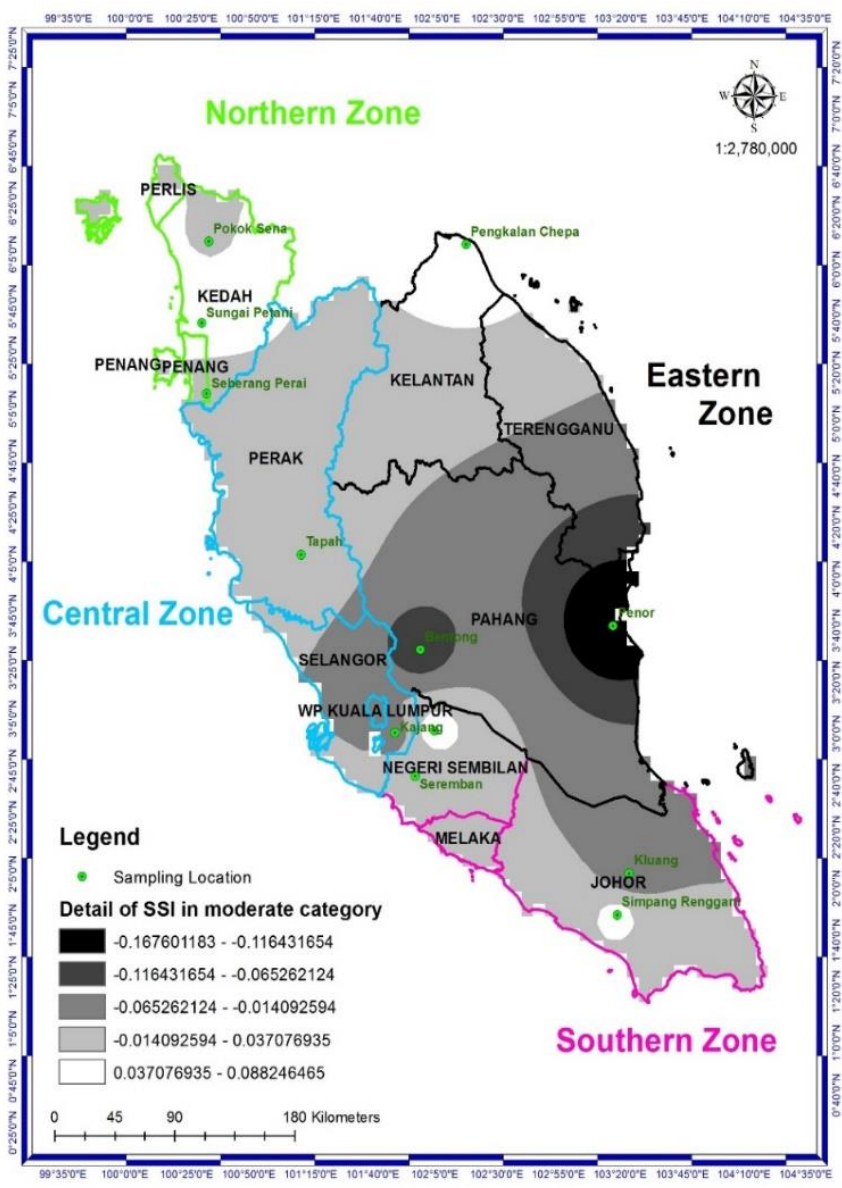

Fig. 5: The Detail Distribution model of Social Support Index for Drug Abuse Inmates at prisons in Peninsular Malaysia, Malaysia.

\section{Conclusion}

This research was done among drug-abuse inmates from Peninsular Malaysia prisons in order to collect data on social support index among these inmates all over Peninsular Malaysia and completed classified the level of SSI in quality of life. GIS and Multivaried Data Analysis were used as tools to analyse the data in this study. 
From the result, the beneficial effects cannot easily be interpreted because of the effects of long-term imprisonment and the entire pattern of results provides strong evidence against expectations of widespread or generalized deleterious effects. The interaction between inmates with other people around them was strongest on those social climate dimensions relating to therapeutic hold and social cohesion. A univariate effect was also observed whereby protective custody prisoners, irrespective of incarceration length, reported that they experienced the environment as less safe than their mainstream counterparts.

\section{Acknowledgement}

The study is funded by the Niche Research Grant Scheme (NRGSKPT), UniSZA/NRGS/2013/RR057, Universiti Sultan Zainal Abidin (UniSZA).

\section{References}

[1] Walmsley, R. (2013). World Prison Population List (10th edition). London.

[2] Allen, C D., Breshears, D D., \& McDowell, N G. (2015). On underestimation of global vulnerability to tree mortality and forest die-off from hotter drought in the Anthropocene. Ecosphere, 6(8), $1-55$.

[3] Chaney, R. A., \& Rojas-Guyler, L. (2015). Spatial patterns of adolescent drug use. Applied Geography, 56, 71-82.

[4] NADA-National Anti-Drugs Agency (2016). Maklumat Dadah 2015. Putrajaya. Retrieved from http://www.adk.gov.my/web/guest/dadah

[5] Chung, M. L., Lennie, T. A., Connell, A., Bailey, A. L., \& Moser D. K. (2011). Depression is associated with cardiovascular disease risk in prison inmates. Circulation, 124(21), 23-30.

[6] Greenberg, G. A, \& Rosenheck, R. A. (2008). Jail incarceration, homelessness, and mental health: a national study. Psychiatric Services (Washington, D.C.).

[7] Butler, T., Kariminia, A., Levy, M., \& Murphy, M. (2004). The self-reported health status of prisoners in New South Wales. Australian and New Zealand journal of public health, 28(4), 344-350.

[8] Morenoff, J. D., \& Harding, D. J. (2014). Incarceration, prisoner reentry, and communities. Annual review of sociology, 40, 411429

[9] Sikkens, E., \& San, M. Van. (2015). It's a hard knock life the survival strategies of Dutch Mulas in Peruvian prisons. Crime Law Soc Change, (63), 121-135

[10] SCMH- Sainsbury Centre for Mental Health, 2008. In the Dark: The Mental Health Implications of Imprisonments for Public Protection. Sainsbury Centre for Mental Health, London.

[11] Buunk, A. P., Peiró, J. M., Rocabert, E., \& Dijkstra, P. (2016) Life satisfaction and status among adolescent law offenders Criminal Behaviour and Mental Health, 26, 94-100 http://doi.org/10.1002/cbm

[12] Bailey, D., Wolfe, D. M., \& Wolfe, C. R. (1994). With a little help from our: Social supports as a source of well-being and of coping with stress. Journal of Sociology and Social Welfare, 21, 127-152.

[13] Lo, A. Y., Xu, B., Chan, F. K., \& Su, R. (2015). Social capital and community preparation for urban flooding in China. Applied Geography, 64, 1-11.

[14] Harp, K. L., Oser, C. B., \& Leukefeld, C. (2012). Social support and crack/cocaine use among incarcerated mothers and non-mothers. Substance Use \& Misuse, 47(6), 686-694. doi:10.3109/10826084.2012.659367

[15] Crow, M. S., \& Smykla, J. O. (2013). Offender Reentry. Jones \& Bartlett Publishers.

[16] Mowen, T. J., and Visher, C. A. (2015). Drug use and crime after incarceration: The role of family support and family conflict. Justice Quarterly, 32, 337-359.

[17] Drago, Francesco, Roberto Galbiati, and Pietro Vertova. (2011) "Prison Conditions and Recidivism." American Law and Economics Review 13:103-130.

[18] Duwe, Grant and Valerie Clark. (2013). "Blessed Be the Social Tie that Binds: The Effects of Prison Visitation on Offender Recidivism." Criminal Justice Policy Review 24: 271-96.
[19] Mears, Daniel P., Xia Wang, and William D. Bales. (2014). "Does a Rising Tide Lift All Boats? Labor Market Changes and Their Effects on the Recidivism of Released Prisoners." Justice Quarterly 31: 822-51.

[20] Listwan, Shelley Johnson, Christopher J. Sullivan, Robert Agnew, Francis T. Cullen, and Mark Colvin. 2013. "The Pains of Imprisonment Revisited: The Impact of Strain on Inmate Recidivism." Justice Quarterly 30: 144-68.

[21] Sulaiman N H, Kamarudin M K A, Toriman M E, Juahir H, Ata F M, Azid A, Abd Wahab N J, Umar R, Khalit S I, Makhtar M, Arfan A \& Sideng U. (2017). Relationship of Rainfall Distribution and Water Level on Major Flood 2014 in Pahang River Basin, Malaysia. EnvironmentAsia, 10(1): 1-8.

[22] Kamarudina M K A., M E. Toriman, H. Juahir, A. Azid, M.B. Gasim, A S M. Saudi, R. Umar, N H. Sulaiman, F M. Ata, A D. Mustafa, M A. Amran, W A. Yusoff, F. Azaman. (2015). Assessment of River Plan Change Using RS and GIS Technique. Jurnal Teknologi, 76 (1): 31-38.

[23] Mustafa, A D., Azman, A., Juahir, H., Yunus, K., Zainal Abidin, I., Sulaiman, N H., Amran, M Z., Osman, M R., Kamarudin, M K A., Gasim, M B. (2015). Geographical Information System (GIS) For Relationship between Dengue Disease and Climatic Factors at Cheras, Malaysia. Malaysian Journal of Analytical Sciences, 19 (6), 1318-1326.

[24] Brownstein, J. S., Green, T. C., Cassidy, T. A., \& Butler, S. F. (2010). Geographic information systems and pharmacoepidemology: using spatial cluster detection to monitor local patterns of prescription opioid abuse. Pharmacoepidemiology and drug safety, 19 (6), 627-637.

[25] D'Ovidio, F D., Leogrande, D., Mancarella, R., Schinzano, A. and Viola, D. (2014). A multivariate analysis of the quality of public transport services. Procedia Economics and Finance 17: 238-247

[26] Nakamura, D. (2014). Social participation and social capital with equity and efficiency: An approach from central-place theory. Applied Geography, 49, 54-57.

[27] Fisher, P. (Ed.). (2005). Re-presenting GIS. John Wiley \& Sons.

[28] Nadal, M., Kumar, V., Schuhmacher, M., \& Domingo, J. L. (2006) Definition and GIS-based characterization of an integral risk index applied to a chemical/petrochemical area. Chemosphere, 64(9), 1526-1535.

[29] Kamarudin, M K A, Toriman, M E., Rosli, M H., Juahir, H., Azid, A., Mohamed Zainuddin, S F., Abdul Aziz, N A. and Sulaiman, W N A. (2015)a. Analysis of Meander Evolution Studies on Effect from Land Use and Climate Change at Upstream Reach of Pahang River, Malaysia. Mitigation and Adaptation Strategies for Global Change, 20(8), 1319-1334.

[30] Zuo, R., Carranza, E. J. M., \& Wang, J. (2016). Spatial analysis and visualization of exploration geochemical data. Earth-Science Reviews, 158, 9-18.

[31] Hijmans, R J., Cameron, S E., Parra, J L., Jones, P G., \& Jarvis, A. (2005). Very high resolution interpolated climate surfaces for global land areas. International journal of climatology, 25(15), 1965-1978.

[32] Fathian, F., Aliyari, H., Kahya, E., \& Dehghan, Z. (2016). Temporal trends in precipitation using spatial techniques in GIS over Urmia Lake Basin, Iran. International Journal of Hydrology Science and Technology, 6(1), 62-81.

[33] Haque, M. N., Shahid, S., Keramat, M., \& Mohsenipour, M. (2016). GIS integration of hydrogeological and geoelectrical data for groundwater potential modeling in the western part of greater Kushtia district of Bangladesh. Water Resources, 43(2), 283-291.

[34] Kazemi, H., Sadeghi, S., \& Akinci, H. (2016). Developing a land evaluation model for faba bean cultivation using geographic information system and multi-criteria analysis (A case study: GonbadKavous region, Iran).Ecological Indicators, 63, 37-47.

[35] Abdullahi, M G., Kamarudin, M K A., Umar, R., Endut, A., Khalit, S I.., Juahir, H. (2017). Night Sky Brightness Assessment in Nigeria Using Environmetric and GIS Technique. International Journal on Advanced Science, Engineering and Information Technology. 7 (1): 28-34.

[36] Alvarado, A., Esteller, M. V., Quentin, E., \& Exposito, J. L. (2016). Multi-criteria decision analysis and GIS approach for prioritization of drinking water utilities protection based on their vulnerability to contamination. Water Resources Management, 30(4), 1549-1566.

[37] Kamarudin, M K A, Toriman, M E., Sulaiman, N H., Ata, F M., Gasim, M B., Muhamad, A., Yusoff, W A., Mokhtar, M., Amran, M A., Abd Aziz, N A. (2015)b. Classification of Tropical River Using Chemometrics Technique: Case Study in Pahang River, 
Malaysia. Malaysian Journal of Analytical Sciences, 19 (5), 10011018.

[38] Ismail, A., Toriman, M E., Juahir, H., Sharifuddin Md Zain, Nur Liyana Abdul Habir, Ananthy Retnam, Mohd Khairul Amri Kamarudin, Roslan Umar, Azman Azid. (2016). Spatial assessment and source identification of heavy metals pollution in surface water using several chemometric techniques. Marine Pollution Bulletin, 106 (1-2), 292-300.

[39] Azid, A., Hafizan J, Ezureen E, Toriman, M. E., Endut, A., Abdul Rahman, M. N., Yunus, K., Kamarudin, M. K. A., Che Hasnam, C. N., Mohd Saudi, A. S., Umar, R. (2015). Identification Source of Variation on Regional Impact of Air Quality Pattern Using Chemometric. Aerosol and Air Quality Research, 5, 1545-1558.

[40] Toriman, M E., Abdllah, S N F., Azizan, I A., kamarudin, M K A., Umar, R., \& Mohamad, N. (2015). Spatial and Temperoral Assessment on Drug Addiction Using Multivariate Analysis and GIS. Malaysian Journal of Analytical Sciences, 19(6), 1361-1373.

[41] Rwoo, M A., Juahir, H., Roslan, N M., Toriman, M E., Endut, A., Azid, A., Che Hasnam, C N., Mohd Saudi, A. S., Kamarudin, M K A., Rwoo, S A., Mustafa, A D. (2016). The assessment of the variation of physico-chemical sources for drinking water quality using chemometrics: A case study at water treatment plants in klang valley. Jurnal Teknologi, 78 (11),1-9.

[42] Oles, M., (2016). Dimensions of Identity and Subjective Quality of Life in Adolescents. Soc Indic Res, 126, 1401-1419. 